\title{
Rhus verniciflua Stokes (RVS) and butein induce apoptosis of paclitaxel-resistant SKOV-3/PAX ovarian cancer cells through inhibition of AKT phosphorylation
}

\author{
Hyeong Sim Choi ${ }^{1}$, Min Kyoung Kim ${ }^{1}$, Youn Kyung Choi ${ }^{2,3}$, Yong Cheol Shin ${ }^{3}$, Sung-Gook Cho ${ }^{4^{*}}$
} and Seong-Gyu $\mathrm{Ko}^{3^{*}}$

\begin{abstract}
Background: Rhus verniciflua Stokes (RVS) belongs to the Anacardiaceae family and traditionally used for cancer treatment. RVS and butein, a major compound of RVS, were known to induce apoptosis via AKT inhibition in cancer cells. Thus, in this study, we investigated the effect of RVS and its derivative compounds (fisetin, quercetin, butein) on cell death in SKOV-3/PAX cells.

Methods: The $80 \%$ ethanol extract of RVS and its derivative compounds (fisetin, quercetin, butein) were prepared. The cytotoxicity was measured by 3-(4,5-dimethylthiazol-2-yl)-2,5-diphenyltetrazolium bromide (MTT) colorimetric assay. Apoptotic cells were detected by staining with propidium iodide (PI) and Annexin V-fluorescein isothiocyanate/ 7-aminoactinomycin D (Annexin V-FITC/7-AAD). The expression level of intracellular signaling related-proteins in apoptosis and growth were measured by western blot assay.

Results: We found that RVS and butein suppressed the growth of SKOV-3/PAX cells in a dose-dependent manner. We also found that RVS and butein produced the cleavage of caspase-9, $-8,-3$, and PARP. Similarly, sub-G 1 phase and Annexin V-FITC positive cells were increased by RVS and butein. Moreover, RVS and butein significantly reduced AKT phosphorylation in SKOV-3/PAX cells. PI3K inhibitor LY294002 caused PARP cleavage supporting our finding.

Conclusion: Our data clearly indicate that RVS and butein induce apoptosis of SKOV-3/PAX cells through inhibition of AKT activation. RVS and butein could be useful compounds for the treatment for paclitaxel resistant-ovarian cancer.
\end{abstract}

Keywords: Rhus verniciflua Stokes, Butein, AKT, Paclitaxel-resistant ovarian cancer, Apoptosis

\section{Background}

Cancer is one of disease and is the second leading cause of death all over the world $[1,2]$. Although the incidence of ovarian cancer is the eighth in developed and developing countries in women. However, the mortality rate for ovarian cancer is the fifth and higher in more developed countries than less developed countries. Further reductions in cancer death rates can be improved by

\footnotetext{
* Correspondence: chosg@ut.ac.kr; epiko@khu.ac.kr

${ }^{4}$ Department of Biotechnology, Korea National University of Transportation,

61 Daehakro, Jeungpyeong-gun, Chungbuk 368-701, Korea

${ }^{3}$ Department of Preventive Medicine, College of Korean Medicine, Kyung

Hee University, 1 Hoegi, Seoul 130-701, Korea

Full list of author information is available at the end of the article
}

applying various therapies including surgery, radiation chemotherapy, hormonal therapy, and chemotherapy [3].

One of the most common chemotherapy agent used for the treatment of ovarian cancer patients are taxanes, such as paclitaxel $[4,5]$. Despite many studies on therapy for decades, there are still considerable problems to be solved such as multi-drug resistant (MDR) [6, 7]. MDR plays a key role in chemotherapy because of existing anti-cancer drugs effectiveness wearing of as tumor build tolerance to them. Although ovarian cancer is sensitive to paclitaxel in early days, tumors ultimately are not in patients because of MDR [8, 9]. One of the acquisition mechanisms to paclitaxel is known as activation of the AKT $[10,11]$. Phosphorylated AKT (p-AKT) is lead 
to an increase in cell growth but it inhibits cell death $[12,13]$. Accordingly, the combination of AKT inhibitors with chemotherapy agent has been shown to sensitize ovarian cancer patients [14, 15].

Rhus verniciflua Stokes (RVS) has many useful effects such as it loosen the extravasated blood in the liver, control inflammation, and help the digestive organs in Donguibogam or a botanical list. Moreover, RVS is documented to be used for treating various diseases such as obesity, allergic inflammatory, allergic contact dermatitis, swelling, angiogenesis, Parkinson's disease, Huntington's disease, and cancer [16-18]. RVS is composed of diverse compounds such as butein, fisetin and quercetin [19].

Previous studies have demonstrated that RVS and butein induce cell death via AKT pathway in cancer cells $[20,21]$. However, it is not reported that RVS or butein is lead to cell death through blocking AKT activation in paclitaxel-resistant ovarian cancer cells. In this study, we wanted to know that whether RVS of ethanol extracted can be induced apoptosis in paclitaxel resistant ovarian cancer. We have shown that RVS was inhibited AKTmediated proliferation via inducing apoptosis. Moreover, butein, a compound of RVS, showed the same results as the RVS. Therefore, our results indicate that RVS and butein may be potential anticancer drug for paclitaxel resistant ovarian cancer.

\section{Methods}

\section{Plant materials}

Toxicodendron vernicifluum Stokes, formerly known as Rhus verniciflua Stokes (RVS) and the common name is Chinese lacquer tree. RVS belongs to the Anacardiaceae family and deciduous tree species $[19,22]$. It is about 10 $\sim 20$ meter in height and divided into yellow endothelial and gray outer. The purpose of its cultivation is mainly used to paint with lacquer collected the sap or get wax from the fruit. Before you use it for food or medicine, it should be removed completely toxic due to the poisonous of RVS [23].

\section{Preparation of RVS extracts and chemical compounds}

$80 \%$ ethanol extract of RVS used in this research was provided from Hanpoong pharm (Jeonju, Republic of Korea). The powder form of RVS was dissolved in $30 \%$ ethanol to make a stock solution and stored at $-80{ }^{\circ} \mathrm{C}$ until ready for use. Fisetin (PubChem CID: 5281614) and quercetin (PubChem CID: 5280343) were purchased from Sigma (St. Louis, MO). Butein (PubChem CID: 5281222) was obtained from Santa Cruz Biotechnology (Santa Cruz, CA, USA).

\section{Cell lines and cell culture}

The paclitaxel resistant ovarian cancer cells, SKOV-3/ PAX cells were provided by Prof. Cho. These cells were grown in Dulbecco's modified Eagle's medium (DMEM) supplemented with $10 \%$ heat-inactivated fetal bovine serum (FBS), $1 \%$ antibiotic-antimycotic solution, and $5 \mathrm{nM}$ of paclitaxel in a humidified atmosphere of $5 \%$ $\mathrm{CO}_{2}$ at $37^{\circ} \mathrm{C}$.

\section{Cell proliferation assay}

For cell proliferation assay, SKOV-3 or SKOV-3/PAX were seeded at $5 \times 10^{3}$ cells in 96 well plates and then treated with paclitaxel $(0,1,10,100$ and $1000 \mathrm{nM})$, RVS $(0,50,100,200$ and $500 \mu \mathrm{g} / \mathrm{mL})$, or butein $(0,2.5,5$ and $10 \mu \mathrm{g} / \mathrm{mL}$ ) for 72 hours. Thereafter, cell viability was performed by 3-(4,5-dimethylthiazol-2-yl)-2,5-diphenyltetrazolium bromide (MTT) colorimetric assay with an absorbance at $570 \mathrm{~nm}$.

\section{FACS analysis}

Dead cells were measured by propidium iodide (PI) staining because PI is bound to DNA and can be used to detect abnormal cell populations. SKOV-3/PAX cells were treated with RVS and butein for 24 hours, and then fixed $70 \%$ ethanol in ice-cold PBS at $-20{ }^{\circ} \mathrm{C}$. Next day, the fixed cells were resuspended in PBS containing $50 \mu \mathrm{g} /$ $\mathrm{mL}$ of PI and $50 \mu \mathrm{g} / \mathrm{mL}$ of RNAse A, and incubated in the dark for 15 minutes at room temperature. The DNA contents of samples were analyzed by FACSCalibur flow cytometer (Becton-Dickinson, San Jose, CA). Apoptotic dead cells were detected by Annexin V-fluorescein isothiocyanate (FITC) and 7-aminoactinomycin D (7-AAD) staining. Annexin V-FITC, staining for phosphatidylserine (PS) in cell membrane, is detected in early apoptosis. 7-AAD is a membrane impermeability dye that is generally stained apoptotic cells and excluded viable cells. SKOV-3/PAX cells were treated with RVS and butein, and then harvested in Annexin V binding buffer. The samples were stained with Annexin V-FITC in the dark for 15 minutes at room temperature and gave more staining with 7-AAD in the same way. 2-dimensional staining to measure apoptosis and necrosis was subjected to FACSCalibur.

\section{Western blot}

Whole lysates, proteins extracted from SKOV-3/PAX were separated by 10-15\% SDS-PAGE according to their molecular weights. Each protein was transferred to nitrocellulose blotting membrane and blotted by appropriate antibodies for following molecules at $4{ }^{\circ} \mathrm{C}$; Anticleaved caspase-9 (sc22182), -p-p38 (sc7973), -p-JNK (sc6254), -ERK (sc1647), and -p-ERK (sc7383) antibodies were purchased from Santa Cruz Biotechnology (Santa Cruz, CA, USA). Anti-cleaved caspase-8 (\#9496), -cleaved caspase-3 (\#9661), -PARP (\#9542), -p-Raf-1 (\#9421), -AKT (\#9272), -p-AKT (S473) (\#9271), -JNK (\#3708), and -p38 (\#9212) antibodies were obtained from Cell Signaling Technology (Danver, MA, USA). Anti- $\alpha$-tubulin (T5168) 
antibody was purchased from Sigma (St. Louis, MO). Next day, the membranes were washed three times in phosphate buffered saline with $0.01 \%$ tween-20 (PBST) and incubated at room temperature for 1 hour with secondary antibodies. The membranes were then washed with PBST three times and visualized the protein bands using an enhanced chemiluminescence detection system (DoGen-Bio, Seoul, Korea) and exposed to X-ray film (Agfa-Gevaert N.V., Mortsel, Belgium).

\section{Statistical analysis}

All experimental data were shown as mean \pm SD and analyzed by Student $t$-test using Microsoft excel software. $P$ value less than 0.05 was considered statistically significant.

\section{Results}

RVS inhibits cell proliferation in chemoresistant SKOV-3 cells We first examined that whether SKOV-3/PAX cells were acquired resistant to paclitaxel from parental cells. As shown in Fig. 1a, paclitaxel inhibited growth of SKOV-3 cells, but not in SKOV-3/PAX cells. Next, we treated

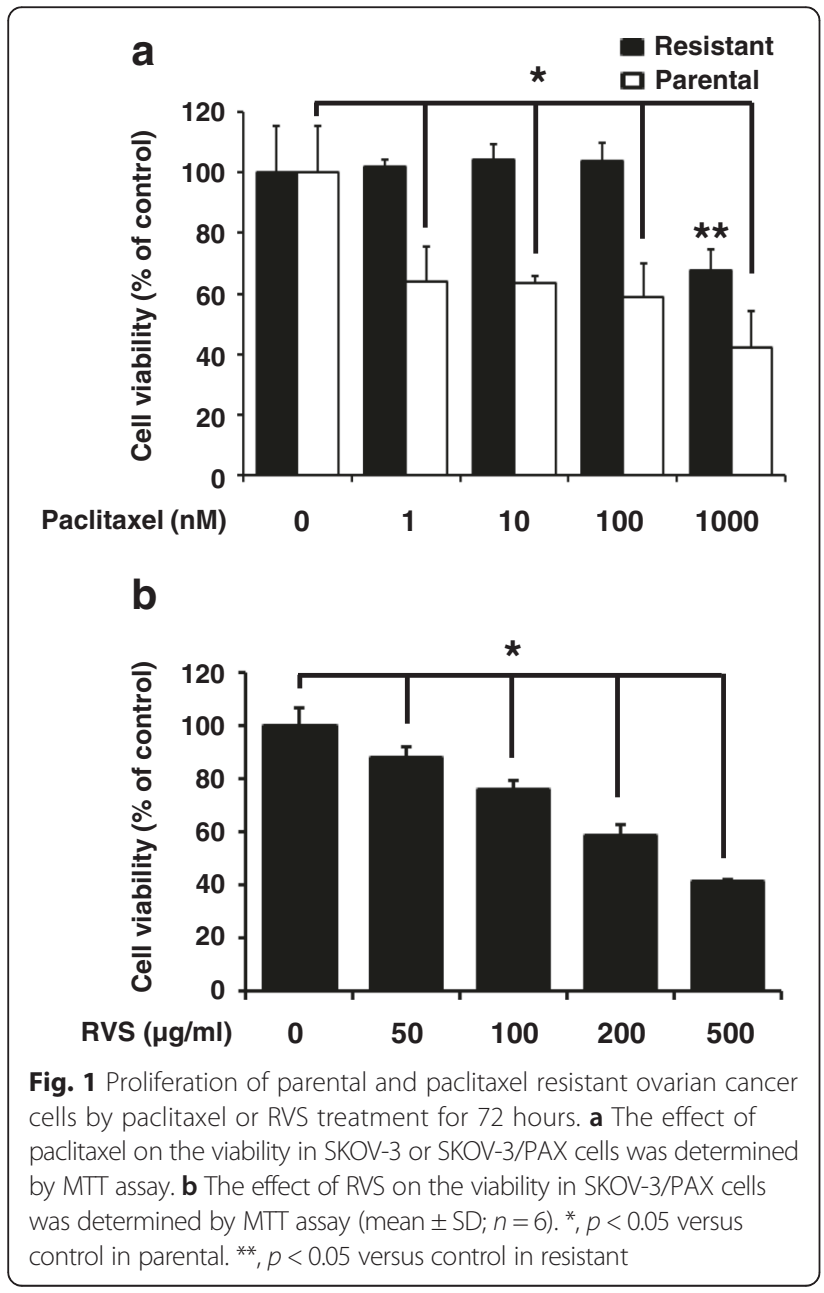

with RVS to identify the anti-proliferation effects in paclitaxel-resistant cells. As shown in Fig. 1b, RVS suppressed in a-dose dependently cell growth in SKOV-3/ PAX cells. Therefore, our results indicate that RVS effectively inhibits the proliferation of paclitaxel-resistant ovarian cancer cells.

\section{RVS induces apoptosis in paclitaxel-resistant ovarian cancer cells}

To determine whether RVS could induce the cell death in SKOV-3/PAX cells, we were treated at various concentrations of RVS. First, we were stained DNA by PI and detected dead cells. The sub- $G_{1}$ phases, dead cells, were increased by RVS in a dose-dependently manner. Especially, dead cell population showed that $500 \mu \mathrm{g} / \mathrm{ml}$ of RVS induced the sub- $G_{1}$ phase to $20.4 \%$ compared with control (Fig. 2a). Next, in order to whether RVS induces cell death inducing apoptosis or necrosis, we performed Annexin V-FITC and 7-AAD staining. SKOV-3/ PAX cells were stained with Annexin V-FITC and 7-AAD, and then measured the proportion of apoptosis and necrosis-related cell death (Fig. 2b). As a result, it was increased the cell death due to apoptosis more than necrosis. Lastly, we were observed the change of apoptosisrelated proteins. Cleaved form of PARP, caspase-9, -8 , and -3 were increased by RVS treatment in SKOV-3/PAX cells (Fig. 2c). Therefore, our data show that RVS induces apoptosis through the caspase-dependent pathway.

\section{Butein suppresses cell proliferation and enhances apoptosis in paclitaxel-resistant ovarian cancer cells} We also wanted to know that whether which compounds of RVS was induced cell death in paclitaxel resistant ovarian cancer cells. As shown in Fig. 3a, butein significantly reduced cell growth than other compounds of RVS, such as fisetin or quercetin. It is reported that fisetin induces apoptosis in human non-small cell lung cancer via inhibiting MAPK signaling pathway and quercetin increases the apoptosis rate of ovarian cancer cells $[24,25]$. To confirm whether butein caused apoptotic cell death, we treated with butein on SKOV-3/PAX cells. Like RVS, butein dose-dependently increased sub- $\mathrm{G}_{1}$ phase (Fig. 3b) and induced the apoptotic-cell death (Fig. 3c). Moreover, butein increased levels of activated caspase-9, -8, -3, and cleaved PARP in SKOV-3/PAX cells (Fig. 3d). Therefore, our data demonstrate that butein is the active compound of RVS and contributes to paclitaxel-resistant ovarian cancer cell apoptosis via caspase-dependent signaling.

\section{RVS and butein disrupt cell growth via AKT pathway in paclitaxel-resistant ovarian cancer cells}

Further our understanding of the molecular effect of RVS or butein in growth control, we performed cells 
a
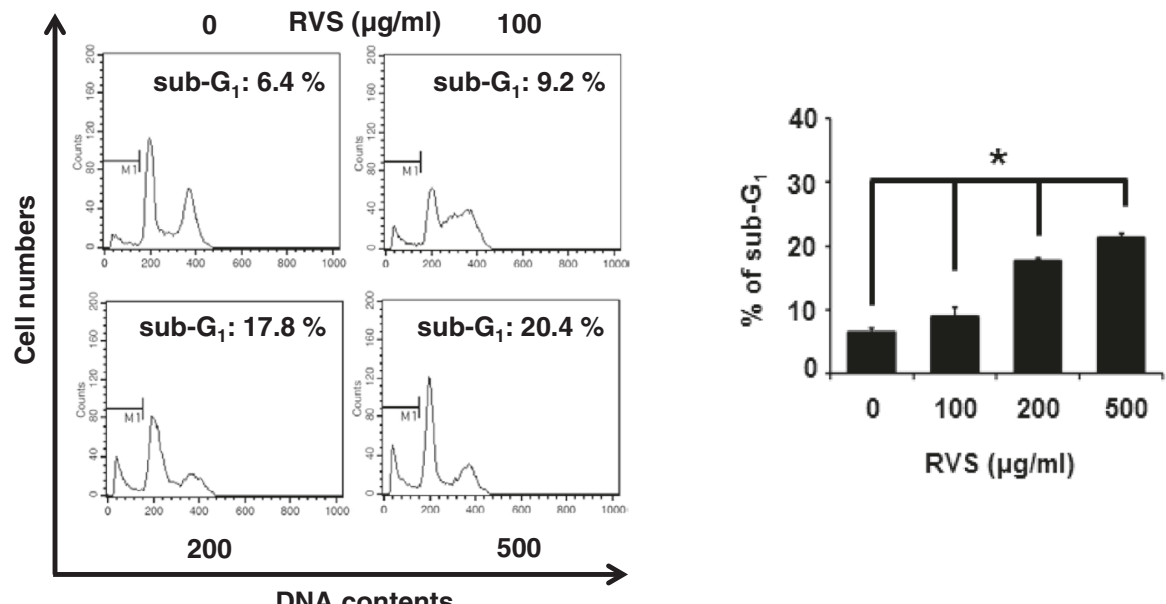

DNA contents

b

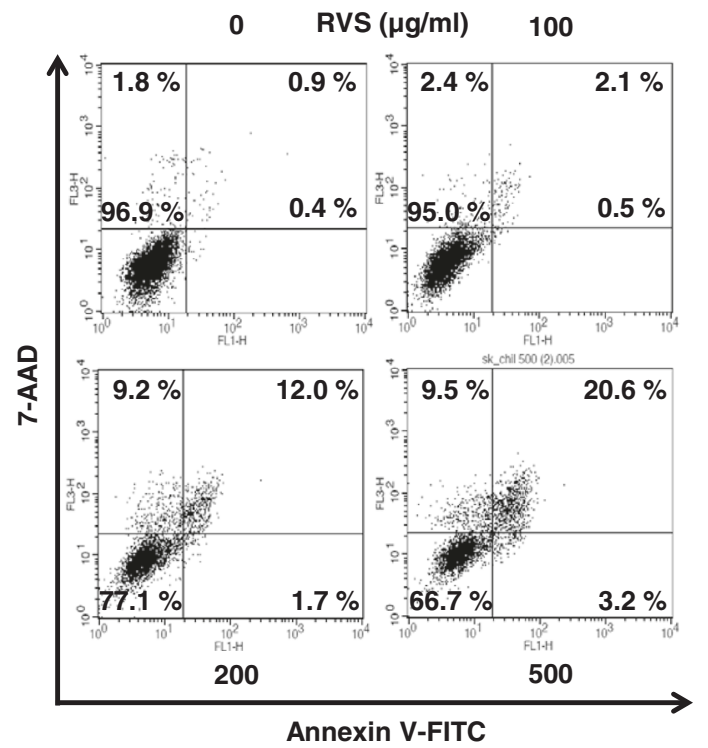

C

RVS ( $\mu \mathrm{g} / \mathrm{ml}) \quad 0100200500$
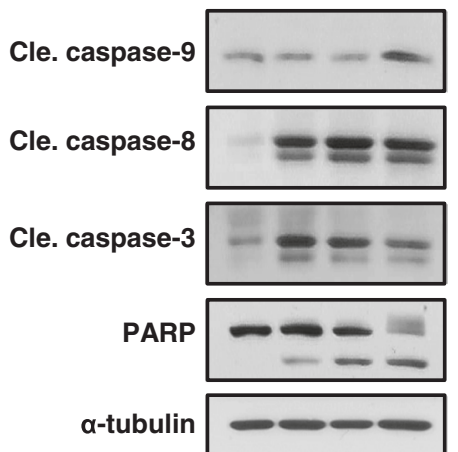

Fig. 2 RVS induces apoptotic-cell death in paclitaxel resistant ovarian cancer cells for 24 hours. a Left panel, the cytotoxic effect of RVS in SKOV-3/PAX cells was determined by PI staining assay. Right panel, data represent quantitative results for left panel (mean $\pm S D ; n=3)$. ${ }^{*}, p<0.05$. $\mathbf{b}$ The dead cells were differentiated between apoptosis and necrosis by Annexin V-FITC and 7-AAD dual staining. c The expression of procaspase-9, cleaved caspase-9, cleaved caspase-8, procaspase-3, caspase-3, and PARP in cell lysates from SKOV-3/PAX cells treated with RVS was determined by Western blot assay

were treated with RVS or butein for 24 hours. When SKOV-3/PAX cells were treated with RVS, phosphorylation of AKT were reduced in a time-dependently manner (Fig. 4a). But phosphorylation of ERK was induces by RVS. In the case of butein, phosphorylation of ERK and p38 were decreased as well as AKT activity (Fig. 4b). Our data showed that inhibition of AKT activity was decreased by both RVS and butein, also the AKT signaling pathway is well known as a key role in cancer cell growth. Therefore, we showed that inhibition of AKT phosphorylation using by AKT inhibitor, LY294002, the PARP cleaved was increased by as much as RVS and butein (Fig. 4c). These results demonstrated that RVS and butein are inducing apoptosis through AKT signaling pathway (Fig. 4d).

\section{Discussion}

Numerous reports are shown that AKT phosphorylation is induced in ovarian cancer patients and paclitaxel-treated in ovarian carcinoma cells. Induction of AKT activation causes tumorigenesis and becomes a problem for treating cancer [26, 27]. It must 

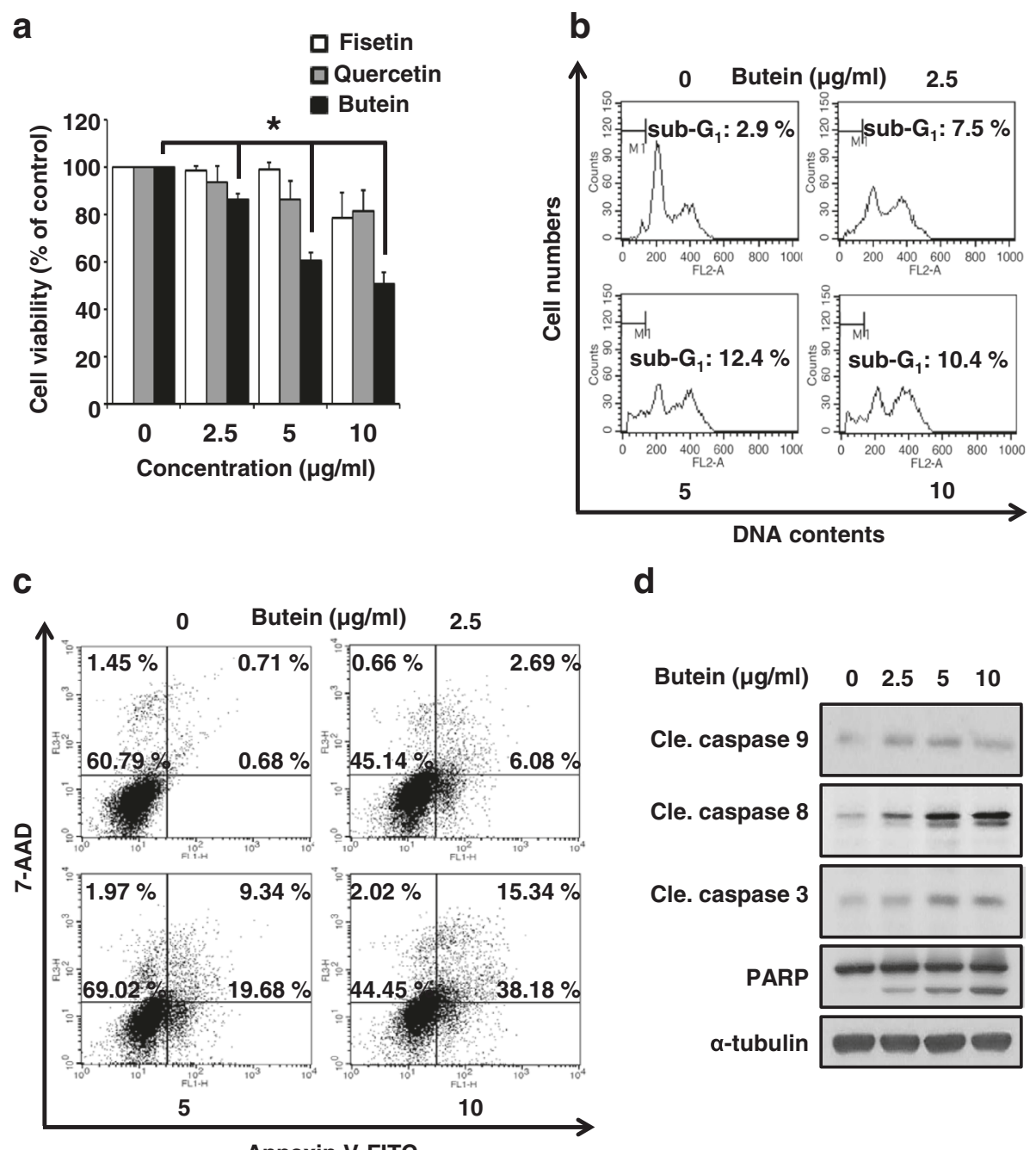

d
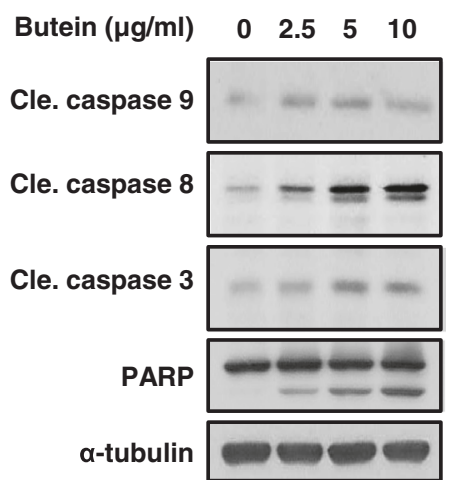

Annexin V-FITC

Fig. 3 The effect of apoptosis in butein-treated SKOV-3/PAX cells. (a) The effect of butein, fisetin, and quercetin on the viability in SKOV-3/PAX cells for 72 hours was determined by MTT assay. (b) The cytotoxic effect of butein in SKOV-3/PAX cells for 24 hours was determined by PI staining assay. Bottom panel, data represent quantitative results for top panel (mean $\pm \mathrm{SD} ; n=3$ ). ${ }^{*}, p<0.05$ versus control. (c) The dead cells were differentiated between apoptosis and necrosis by Annexin V- FITC and 7-AAD dual staining. (d) The expression of procaspase-9, cleaved caspased-9,

cleaved caspase-8, procaspase-3, caspase-3, and PARP in cell lysates from SKOV-3/PAX cells treated with butein were determined by Western blot assay

be treated together inhibiting of AKT activity as well as increasing apoptosis [28, 29]. Recent studies showed that RVS reduces AKT phosphorylation in gastric cancer cell lines [30] and that n-butanol extract form RVS decreases LPS-induced AKT activation in macrophage RAW 264.7 cells [31]. Therefore, we evaluated the effects of RVS in paclitaxel-resistant ovarian cancer cell lines.

The results indicate that RVS was lead to apoptosis via both accumulation of cleaved PARP form and suppression of AKT activation in a dose-dependent manner. Furthermore, we conducted experiments to know what compounds of RVS have these capabilities. Among the three compounds, butein effected best, reducing the proliferation of SKOV-3/PAX cells. Butein, a bioactive flavonoid [32, 33], was effective for cancer treatment through apoptosis pathway such as caspases and PARP. Also, Butein affected the cell proliferation via repressing AKT phosphorylation in cervical cancer cells and AKT-dependent phosphorylation of hTERT in leukemia cells [32, 34]. It is reported that other compounds, fisetin and quercetin, induce apoptosis in cancer cells, but slightly inhibited proliferation in SKOV-3/PAX cells $[24,25]$. Lastly, after treatment of SKOV-3/PAX cells with PI3K inhibitor LY294002, the function of AKT was repressed. The result is RVS and butein can induce SKOV-3/PAX cell apoptosis by reducing $\mathrm{AKT}$ pathway activation. Accordingly, the 


\section{a}

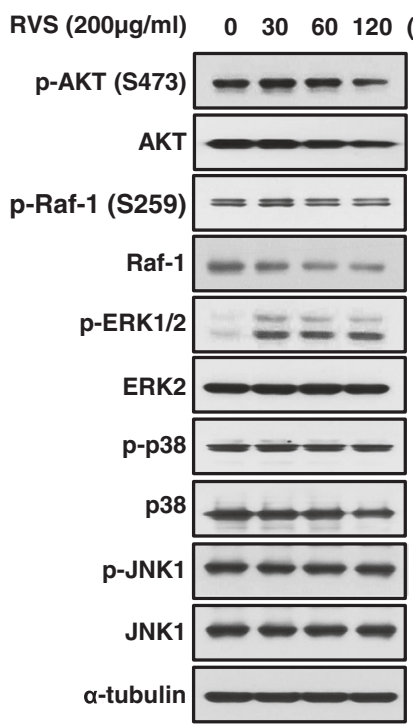

C

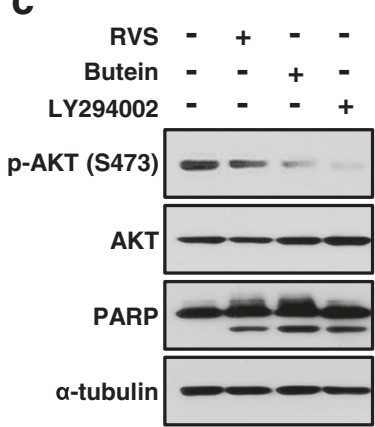

b

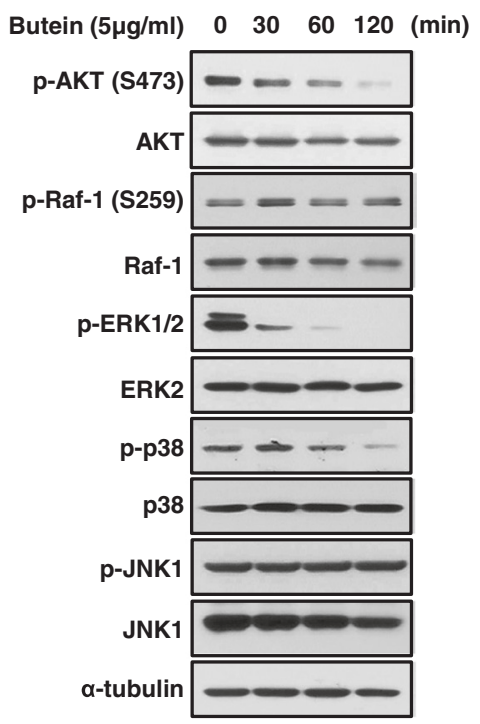

d

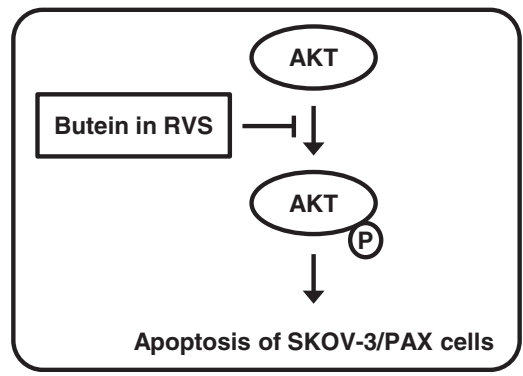

Fig. 4 RVS and butein inhibit AKT signaling in SKOV-3/PAX cells for 2 hours. (a and b) The expression of AKT, Raf-1, ERK, p38, and JNK in cell lysates from SKOV-3/PAX cells treated with RVS or butein were determined by Western blot assay. (c) SKOV-3/PAX cells were pretreated with AKT inhibitor, LY294002 (50 MM) for 1 hour and then added with RVS or butein for another 24 hours. The expression levels of AKT phosphorylation and PARP cleavage were determined by Western blot assay. (d) A schematic model for the apoptosis via inhibition of AKT activity by RVS or butein

present study suggested that the inhibiting AKT phosphorylation is a key role for the apoptosis of paclitaxelresistant ovarian cancer cells.

\section{Conclusion}

We show that RVS and its active compound, butein, may enhance apoptosis and reduce proliferation through the inhibition of AKT activation in paclitaxel resistantovarian cancer. Therefore, our results suggested that RVS could be useful for the chemotherapy of drugresistant cancer and more researches are needed to further a detailed mechanism.

\section{Ethics}

This study used cell lines commercially available, thereby not requiring the ethics.

\section{Availability of data and materials}

Data are all contained within the paper.

\section{Competing interests}

The authors declare that they have no competing interests.

\section{Authors' contributions}

HSC designed the research, performed all laboratory experiments, analyzed data, and drafted the manuscript. SGC conceived the experiments, analyzed data, and revised the manuscript. MKK assisted all laboratory experiments. YKC helped to modify the manuscript. YCS carried out the literature search and SGK supervised the research. All authors have read and approved the final manuscript.

\section{Acknowledgements}

This work was supported by a grant from Korean Medicine R\&D project of the Ministry Of Health and Welfare (B120014). 


\section{Author details}

Department of Science in Korean Medicine, Graduate School, Kyung Hee University, 1 Hoegi, Seoul 130-701, Korea. ${ }^{2} J$ eju International Marine Science Center for Research and Education, Korea Institute of Ocean Science \& Technology (KIOST), Jeju 695-975, Korea. ${ }^{3}$ Department of Preventive Medicine, College of Korean Medicine, Kyung Hee University, 1 Hoegi, Seou 130-701, Korea. ${ }^{4}$ Department of Biotechnology, Korea National University of Transportation, 61 Daehakro, Jeungpyeong-gun, Chungbuk 368-701, Korea.

\section{Received: 8 January 2016 Accepted: 21 April 2016}

\section{Published online: 27 April 2016}

\section{References}

1. Siegel RL, Miller KD, Jemal A. Cancer statistics, 2015. CA Cancer J Clin. 2015; 65(1):5-29.

2. Torre L, Siegel RL, Jemal A. Global Cancer Facts \& Figures. 3rd ed. Atlanta: American Cancer Society; 2015.

3. Li Y, Jiang Y, Wan Y, Zhang L, Tang W, Ma J, Wu S, Cheng W. Medroxyprogestogen enhances apoptosis of SKOV-3 cells via inhibition of the PI3K/Akt signaling pathway. J Biomed Res. 2013;27(1):43-50.

4. DiSaia PJ, Bloss JD. Treatment of ovarian cancer: new strategies. Gynecol Oncol. 2003;90(2 Pt 2):S24-32

5. Lin YH, Chen BY, Lai WT, Wu SF, Guh JH, Cheng AL, Hsu LC. The Akt inhibitor MK-2206 enhances the cytotoxicity of paclitaxel (Taxol) and cisplatin in ovarian cancer cells. Naunyn Schmiedebergs Arch Pharmacol. 2015:388(1):19-31.

6. Borst $P$, Schinkel $A H$. P-glycoprotein $A B C B 1$ : a major player in drug handling by mammals. J Clin Invest. 2013;123(10):4131-3.

7. Sui H, Fan ZZ, Li Q. Signal transduction pathways and transcriptional

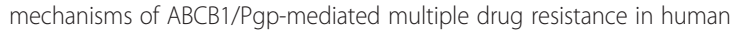
cancer cells. J Int Med Res. 2012;40(2):426-35.

8. Horwitz SB, Cohen D, Rao S, Ringel I, Shen HJ, Yang CP. Taxol: mechanisms of action and resistance. J Natl Cancer Inst Monogr. 1993;15:55-61.

9. Rowinsky EK. The development and clinical utility of the taxane class of antimicrotubule chemotherapy agents. Annu Rev Med. 1997:48:353-74

10. Ling $X$, Bernacki RJ, Brattain MG, Li F. Induction of survivin expression by taxol (paclitaxel) is an early event, which is independent of taxol-mediated G2/M arrest. J Biol Chem. 2004;279(15):15196-203.

11. West KA, Castillo SS, Dennis PA. Activation of the PI3K/Akt pathway and chemotherapeutic resistance. Drug Resist Updat. 2002;5(6):234-48.

12. Mabuchi S, Ohmichi M, Kimura A, Hisamoto K, Hayakawa J, Nishio Y, Adachi K, Takahashi K, Arimoto-Ishida E, Nakatsuji Y, et al. Inhibition of phosphorylation of BAD and Raf-1 by Akt sensitizes human ovarian cancer cells to paclitaxel. J Biol Chem. 2002:277(36):33490-500.

13. Karam AK, Santiskulvong C, Fekete M, Zabih S, Eng C, Dorigo O. Cisplatin and PI3kinase inhibition decrease invasion and migration of human ovarian carcinoma cells and regulate matrix-metalloproteinase expression. Cytoskeleton (Hoboken). 2010;67(8):535-44.

14. Altomare DA, Wang HQ, Skele KL, De Rienzo A, Klein-Szanto AJ, Godwin AK, Testa JR. AKT and mTOR phosphorylation is frequently detected in ovarian cancer and can be targeted to disrupt ovarian tumor cell growth. Oncogene. 2004;23(34):5853-7.

15. Sasano T, Mabuchi S, Kuroda H, Kawano M, Matsumoto Y, Takahashi R, Hisamatsu T, Sawada K, Hashimoto K, Isobe A, et al. Preclinical Efficacy for AKT Targeting in Clear Cell Carcinoma of the Ovary. Mol Cancer Res. 2015; 13(4):795-806

16. Choi W, Jung H, Kim K, Lee S, Yoon S, Park J, Kim S, Cheon S, Eo W, Lee S. Rhus verniciflua stokes against advanced cancer: a perspective from the Korean Integrative Cancer Center. J Biomed Biotechnol. 2012;2012:874276.

17. Hong MH, Kim JH, Lee SY, Go HY, Kim JH, Shin YC, Kim SH, Ko SG. Early antiallergic inflammatory effects of Rhus verniciflua Stokes on human mast cells. Phytother Res. 2010;24(2):288-94.

18. Park DK, Lee YG, Park HJ. Extract of Rhus verniciflua Bark Suppresses 2,4Dinitrofluorobenzene-Induced Allergic Contact Dermatitis. Evid Based Complement Alternat Med. 2013;2013:879696

19. Kim JH, Shin YC, Ko SG. Integrating traditional medicine into modern inflammatory diseases care: multitargeting by Rhus verniciflua Stokes. Mediators Inflamm. 2014;2014:154561.

20. Khan N, Adhami VM, Afaq F, Mukhtar H. Butein induces apoptosis and inhibits prostate tumor growth in vitro and in vivo. Antioxid Redox Signal. 2012;16(11):1195-204.
21. Na CH: Molecular mechanism by which Rhus Verniciflua Stokes induces apoptosis in SK-OV-3/PAC, chemoresistance ovarian cells. 2015:1-29. http:// www.dcollection.net/handler/khu/000000164759

22. Shin SH, Koo KH, Bae JS, Cha SB, Kang IS, Kang MS, Kim HS, Heo HS, Park MS, Gil GH, et al. Single and 90-day repeated oral dose toxicity studies of fermented Rhus verniciflua stem bark extract in Sprague-Dawley rats. Food Chem Toxicol. 2013;55:617-26.

23. Byun JS, Han YH, Hong SJ, Hwang SM, Kwon YS, Lee HJ, Kim SS, Kim MJ, Chun W. Bark Constituents from Mushroom-detoxified Rhus verniciflua Suppress Kainic Acid-induced Neuronal Cell Death in Mouse Hippocampus. Korean J Physiol Pharmacol. 2010;14(5):279-83.

24. Kang KA, Piao MJ, Madduma Hewage SR, Ryu YS, Oh MC, Kwon TK, Chae S, Hyun JW. Fisetin induces apoptosis and endoplasmic reticulum stress in human non-small cell lung cancer through inhibition of the MAPK signaling pathway. Tumour Biol 2016; pp 1-10. DOI 10.1007/s13277-016-4864-x

25. Ren MX, Deng XH, Ai F, Yuan GY, Song HY. Effect of quercetin on the proliferation of the human ovarian cancer cell line SKOV-3. Exp Ther Med. 2015;10(2):579-83.

26. Datta SR, Brunet A, Greenberg ME. Cellular survival: a play in three Akts. Genes Dev. 1999:13(22):2905-27.

27. Urban BC, Collard TJ, Eagle CJ, Southern SL, Greenhough A, HamdollahZadeh M, Ghosh A, Poulsom R. BCL-3 expression promotes colorectal tumorigenesis through activation of AKT signalling. 2015. DOI 10.1136/ gutjnl-2014-308270

28. Falasca M. PI3K Akt signalling pathway specific inhibitors: a novel strategy to sensitize cancer cells to anti-cancer drugs. Curr Pharm Des. 2010;16(12): 1410-6.

29. Zhang W, Cai J, Chen S, Zheng X, Hu S, Dong W, Lu J, Xing J, Dong Y. Paclitaxel resistance in MCF-7/PTX cells is reversed by paeonol through suppression of the SET/phosphatidylinositol 3-kinase/Akt pathway. Mol Med Rep. 2015;12(1):1506-14.

30. Kim JH, Go HY, Jin DH, Kim HP, Hong MH, Chung WY, Park JH, Jang JB,

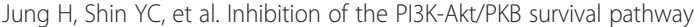
enhanced an ethanol extract of Rhus verniciflua Stokes-induced apoptosis via a mitochondrial pathway in AGS gastric cancer cell lines. Cancer Lett. 2008;265(2):197-205

31. Jung $\mathrm{CH}$, Kim JH, Kim JH, Chung JH, Choi HS, Seo JB, Shin YC, Kim SH, Ko SG Anti-inflammatory effect of Rhus verniviflua Stokes by suppression of iNOSmediated Akt and ERK pathways: in-vitro and in-vivo studies. J Pharm Pharmacol. 2011;63(5):679-87.

32. Bai $X, M a Y$, Zhang $G$. Butein suppresses cervical cancer growth through the PI3K/KT/mTOR pathway. Oncol Rep. 2015;33(6):3085-92.

33. Song NJ, Yoon HJ, Kim KH, Jung SR, Jang WS, Seo CR, Lee YM, Kweon DH, Hong JW, Lee JS, et al. Butein is a novel anti-adipogenic compound. J Lipid Res. 2013;54(5):1385-96.

34. Moon DO, Kim MO, Lee JD, Choi YH, Kim GY. Butein suppresses c-Mycdependent transcription and Akt-dependent phosphorylation of hTERT in human leukemia cells. Cancer Lett. 2009;286(2):172-9.

\section{Submit your next manuscript to BioMed Central and we will help you at every step:}

- We accept pre-submission inquiries

- Our selector tool helps you to find the most relevant journal

- We provide round the clock customer support

- Convenient online submission

- Thorough peer review

- Inclusion in PubMed and all major indexing services

- Maximum visibility for your research

Submit your manuscript at www.biomedcentral.com/submit
) Biomed Central 